\title{
Aspectos da realidade social de crianças e adolescentes atendidos em Serviço de Referência para Filariose Bancroftiana, Recife, Estado de Pernambuco
}

\author{
Aspects of the social realities of children and adolescents seen at a Reference \\ Service for Bancroftian filariasis in Recife, State of Pernambuco
}

\author{
Denise Mattos $^{1,2,3}$, Solange Mota $^{1}$ e Gerusa Dreyer ${ }^{1,3}$
}

\begin{abstract}
RESUMO
Os autores abordam aspectos da realidade social de crianças e adolescentes residentes em Jaboatão dos Guararapes/PE, diagnosticados como portadores de infecção filarial bancroftiana e tratados no Núcleo de Ensino, Pesquisa e Assistência em Filariose da Universidade Federal de Pernambuco (Centro de Ciências da Saúde), um serviço terciário de referência para filariose. Quantificam e classificam as condições de moradia como subumanas, estando em relação direta com a manutenção da transmissão da bancroftose, e alertam para a necessidade de decisão política quanto à implementação de obras de saneamento básico.
\end{abstract}

Palavras-chaves: Filariose bancroftiana. Controle. Exclusão social. Trabalho infantil. Alcoolismo.

\begin{abstract}
The authors report on aspects of the social realities of children and adolescents living in Jaboatão dos Guararapes, State of Pernambuco, who were diagnosed with Bancroftian filariasis infection and were treated at the Filariasis Teaching, Research and Care Center of the Federal University of Pernambuco (Health Sciences Center), which is a tertiary-level reference service for filariasis. The patients' housing conditions were quantified and classified as subhuman, with a direct relationship with the maintenance of Bancroftian filariasis transmission, and the authors highlight the need for political decisions regarding the implementation of basic sanitation projects.
\end{abstract}

Key-words: Bancroftian filariasis. Control. Social stigma. Child workforce. Alcoholism.

A filariose bancroftiana, também conhecida como elefantíase, é causada pela Wuchereria bancrofti e atinge cerca de 100 milhões de pessoas no mundo, sendo prevalente em 83 países de climas tropical e subtropical ${ }^{32}$. Aproximadamente, um terço desses indivíduos reside na Índia, outro terço encontra-se distribuído no continente africano e o restante, predominantemente, na região ocidental do Pacífico e no sudeste da Ásia. As Américas contribuem com $0,3 \%$ da prevalência mundial, sendo o Haiti o país de maior número de casos. No Brasil, como na maioria das regiões endêmicas, a bancroftose é transmitida pelo vetor conhecido no nordeste como muriçoca, mosquito da espécie Culex quinquefasciatus. Os únicos focos de transmissão ativa estão no Grande Recife (Pernambuco) e em Maceió (Alagoas). Na década de 1960, Belém do Pará era considerada como o foco de maior prevalência, encontrando-se, hoje, já em vias de ser reconhecida como livre de transmissã $0^{12}$. Na região metropolitana do Recife, os municípios de maior endemicidade são Recife, Olinda, Jaboatão dos Guararapes e Paulista, sendo Jaboatão dos Guararapes o de maior densidade de parasitemia e de mosquitos com maior índice de infectividade ${ }^{20}$.

Estudos publicados anteriormente já alertaram para a importância social da filariose nas suas interfaces, ressaltando, sobretudo, as condições socioeconômicas em que vivem as populações infectadas e os custos financeiros do agravo, diretos ou indiretos ${ }^{2} 1027$. As desigualdades que existem nas áreas endêmicas não estão circunscritas apenas ao agravo provocado pela doença incapacitante ${ }^{31}$, e as condições de vida tornam-se 0 espelho maior das repercussões sociais mais amplas da doença. Não se trata de um processo de risco condicionado principalmente pela responsabilidade individual como acontece com outras

1.Núcleo de Ensino, Pesquisa e Assistência em Filariose, Hospital das Clínicas, Universidade Federal de Pernambuco, Recife, PE. 2. Serviço Social, Hospital das Clínicas, Universidade Federal de Pernambuco, Recife, PE. 3.Organização Não governamental Amaury Coutinho para Doenças Endêmicas e Tropicais, Recife, PE.

Órgão financiador: $0 \mathrm{NG}$ Amaury Coutinho.

Endereço para correspondência: Dr ${ }^{a}$ Denise Mattos. Organização Não Governamental Amaury Coutinho para Doenças Endêmicas e Tropicais. R. Conselheiro Portela 665/sala 120, Graças, 52020-030 Recife, PE.

Telefax: $55813426-4348$

e-mail: mattos.denise@gmail.com

Recebido para publicação em: 15/06/2007

Aceito em: 28/01/2008 
doenças, como a hipertensão arterial, cuja prevenção e controle estão em íntima associação com mudanças nos hábitos de vida ${ }^{29}$; na filariose, a responsabilidade maior é do estado. Na realidade, a filariose aparece como consequiência e não como causa da precária condição da realidade social das áreas endêmicas. Assim, há uma relação perversa nos países em desenvolvimento, e o impacto negativo da inconsistência de um processo político decisório - que não é só brasileiro, mas identificado mundialmente - independe da filariose. Se assim não fosse, como explicar que a probabilidade de morte do homem entre os 15 e 60 anos de idade no Lesoto é de $84,5 \%$ e na Suécia, de $8,6 \% 33$ ? A questão conduz à certeza de que, independentemente dos agravos de saúde de cada país, para os quais a ciência já tem a solução, é imperativo centrar a avaliação do mérito das pesquisas científicas nas respostas que deverão produzir um impacto positivo na qualidade de vida dos portadores de doenças. Isso só poderá ocorrer se a ciência levar em conta, como variável de extrema importância, a realidade social onde os pacientes estão inseridos.

Os estudos acerca da bancroftose em crianças e adolescentes têm sido realizados, principalmente, sob o vértice da infecção/ doença per si, isto é, da transmissão, das manifestações clínicas e do tratamento antifilarial ${ }^{46811162526}$. Pouco se conhece sobre a quantificação das condições socioeconômicas dessa parcela de menor idade infectada e de suas famílias. 0 presente estudo foi conduzido com o objetivo de melhor detalhar o perfil social de menores infectados pela filariose bancroftiana vivendo em Jaboatão dos Guararapes, área endêmica de maior índice de transmissão no Brasil ${ }^{20}$.

\section{MATERIAL E MÉTODOS}

A população estudada foi formada por crianças e adolescentes autóctones de Jaboatão dos Guararapes (Grande Recife, PE), encaminhados ao Núcleo de Ensino, Pesquisa e Assistência em Filariose para tratamento antifilarial pelo Programa de Controle da Filariose da Secretaria Municipal de Saúde de Jaboatão dos Guararapes, no período de junho a novembro de 2003. Esse estudo foi conduzido em paralelo a um estudo maior sobre eficácia de tratamento antifilarial ${ }^{28}$, aprovado pelo Comitê de Ética do Centro de Ciências da Saúde/UFPE. Os responsáveis assinaram o termo de consentimento de participação após esclarecimento, assim como os adolescentes com 16 anos ou mais.

Foi aplicado um questionário de investigação social a cada usuário com a participação de seu responsável. Por ser constituído de perguntas abertas e fechadas, o questionário foi aplicado de forma dialógica. As informações abrangiam a identificação do menor infectado (nome, idade, gênero), a escolarização e a identificação da escola (nome, pública ou privada), a religião, a composição familiar, a experiência em alguma atividade laborativa, o tipo de locação/construção e as condições sanitárias da unidade domiciliar e da área de entorno, o número de quartos e de pessoas ocupantes do mesmo dormitório, o uso de drogas lícitas e/ou ilícitas e a atividade sexual, sendo este último aspecto perguntado apenas aos adolescentes. Quando o entrevistado não sabia dar alguma informação solicitada, a mesma era obtida através do responsável. As perguntas referentes aos responsáveis foram dirigidas à situação atual de emprego, à renda familiar mensal, às fontes da renda, à escolarização, ao seguro social e ao hábito de ingerir bebida alcoólica. Aos demais componentes da família, consangüíneos ou não, perguntou-se acerca da situação de trabalho, de hábito alcoólico e de contribuição para as despesas da casa. Visitas domiciliares foram realizadas quando as informações eram imprecisas (quer por parte do usuário, quer por dificuldade do entrevistador em entender as condições reais relatadas) ou incompletas. Todos os usuários incluídos no estudo receberam tratamento antifilarial ${ }^{28} \mathrm{e}$ informações gerais sobre a doença bancroftiana e a transmissão da infecção.

Os dados foram armazenados no programa Excel versão 2002 e foi utilizada a estatística descritiva para a confecção das tabelas e dos demais resultados apresentados.

Definição de termos. Abandono à escola: não concluiu o ensino fundamental, independentemente da série cursada.

Analfabeto: maior de 8 anos de idade que não lê e não escreve ou apenas assina o nome, independentemente de estar freqüentando alguma série do ensino fundamental.

Autóctone: nativo; indivíduo nascido e que vive na mesma região geográfica quando do diagnóstico do agravo.

Banheiro: cômodo da unidade domiciliar com chuveiro e aparelho sanitário ${ }^{15}$.

Criança e adolescente: pessoas com até 12 anos incompletos e dos 12 aos 18 anos, respectivamente 5

De 1 a 8 anos de estudo: frequientou uma das oito séries do ensino fundamental ou concluiu e não deu continuidade aos estudos.

Destino do lixo: coletado por serviço público ou colocado a céu aberto, quando exposto pela população em caçambas, em via pública ou em córregos, rios ou terrenos baldios.

Esgoto a céu aberto: forma utilizada para esgotamento de excretas humanas em valetas abertas, córregos, mangues e rios próximos ou fossas sem vedação adequada.

Família: somatório das pessoas que habitam sob o mesmo teto (coabitantes/conviventes), independentemente de relação consangüínea.

Linha de pobreza: valor da per capita mensal familiar situada abaixo de US\$1,00/dia, ajustado por diferenças do custo de vida entre países e entre períodos de tempo ${ }^{24}$. Na época do estudo, esse valor era equivalente a $\mathbf{R} \$ 26,30$.

Mais de 8 anos de estudo: freqüentou uma das três séries do ensino médio ou concluiu e não deu continuidade aos estudos.

Pré-escolar: freqüenta uma das séries do ensino préalfabetização.

Renda mensal familiar: somatório de todos os ganhos de qualquer natureza auferidos por qualquer membro da família.

Renda per capita: renda mensal familiar dividida pelo número dos coabitantes e expressa em moeda nacional.

Responsável: genitor e/ou genitora biológicos ou a pessoa responsável pela guarda judicial ou espontânea da criança e/ou do adolescente. 
Trabalho formal: qualquer atividade laboral exercida pelo menor, responsável ou outro coabitante, registrada em carteira de trabalho e com remuneração definida.

Trabalho informal: qualquer atividade laboral exercida pelo menor, responsável ou outro coabitante, com remuneração flutuante e dependente do serviço realizado ou prestado a outro, sem relação de emprego. 0 valor foi calculado como média entre 0 mais alto e o mais baixo montante mensal recebido devido à característica de flutuação.

\section{RESULTADOS}

Foram estudados 95 usuários vivendo em 76 famílias. Oitenta e três $(87,3 \%)$ deles compareceram à entrevista social com os responsáveis biológicos, a maioria (70,5\%) dos quais representados pela mãe. Os demais $12(12,7 \%)$ menores moravam com pessoas consangüíneas ou não, porque um ou ambos os genitores não assumiram a sua educação. Apenas um caso foi motivado por decisão judicial em face de abuso sexual sofrido pela criança. Foi obtida uma média de 5,6 pessoas por unidade domiciliar. Em 100\% das famílias, havia a presença da responsável feminina. A figura masculina foi representada em $63,2 \%$ dessas famílias. A duração média de cada entrevista foi de 45 minutos, variando de 30 a 55 minutos.

As informações sobre o uso de bebida alcoólica encontram-se na Tabela 1. Uma criança de 11 anos e um adolescente de 15 , ambos do gênero masculino, informaram ter tido experiência com maconha, descontinuando o uso. A iniciação à atividade sexual foi verbalizada por 49 adolescentes (Tabela 1). Todos declararam fazer uso regular de preservativo. Seis adolescentes do gênero masculino informaram não ter iniciado ainda a vida sexual, por seguirem as orientações religiosas que professam. Trinta e dois adolescentes declararam não ter religião. A Tabela 1 mostra os que informaram seguir alguma religião. Na Tabela 2, encontra-se a escolaridade dos usuários e de seus responsáveis. 0 índice de evasão do ensino fundamental foi de $25,3 \%$ entre os adolescentes e maior entre os responsáveis, chegando a $67,1 \%$

Tabela 1 - Características de gênero e idade da população estudada, assim como religião, bábito alcoólico e iniciação à atividade sexual.

\begin{tabular}{llll}
\hline Características & Total & Feminino & Masculino \\
\hline Número de pacientes & $95(100,0 \%)$ & $39(41,1 \%)$ & $56(58,9 \%)$ \\
Idade (anos) média (variação) & $13,7(5-18)$ & $12,7(5-18)$ & $14,3(8-18)$ \\
$\quad$ crianças & 28 & 17 & 11 \\
$\quad$ idade (anos) média (variação) & $9,7(5-11)$ & $9,4(5-11)$ & $10,0(8-11)$ \\
adolescentes & 67 & 22 & 45 \\
$\quad$ idade (anos) média (variação) & $15,4(12-18)$ & $15,3(12-18)$ & $15,4(12-18)$ \\
$\quad$ vida sexual & $49(73,1)$ & $18(26,8 \%)$ & $31(46,2 \%)$ \\
$\quad$ iniciada aos 10 anos & 1 & 1 & 0 \\
$\quad$ iniciada aos 12 anos & 14 & 5 & 9 \\
$\quad$ iniciada aos 13 anos & 19 & 10 & 9 \\
$\quad$ iniciada acima dos 14 anos & 15 & 2 & 13 \\
Ingesta alcoólica* & $40(42,1 \%)$ & $2(2,1 \%)$ & $38(40,0 \%)$ \\
Têm religião & $63(66,3 \%)$ & $31(32,6 \%)$ & $32(33,7 \%)$ \\
\hline
\end{tabular}

* Dois adolescentes do gênero masculino faziam uso diário; um deles iniciou aos 11 anos de idade. entre as mulheres e 56,3\% entre os homens. Apenas duas $(7,1 \%)$ crianças estudavam em escola privada do bairro, sendo as demais e os adolescentes matriculados em escolas públicas municipais e/ou estaduais. A Tabela 3 mostra a relação formal e informal estabelecida no mercado de trabalho pelos 429 coabitantes (95 usuários, 48 responsáveis do gênero masculino, 76 responsáveis do feminino, 24 avós, 168 irmãos dos usuários e 18 outros, parentes ou não, que compunham o grupo familiar). Na relação

Tabela 2 - Nível de escolaridade dos usuários e de seus responsáveis.

\begin{tabular}{|c|c|c|c|c|c|c|c|c|}
\hline & \multicolumn{2}{|c|}{ Pré-escolar } & \multicolumn{2}{|c|}{ Analfabetos } & \multicolumn{2}{|c|}{ Até $8 \mathrm{a}$} & \multicolumn{2}{|c|}{ Mais de $8 \mathrm{a}$} \\
\hline & $\mathrm{n}^{\underline{0}}$ & $\%$ & $\mathrm{n}^{\underline{0}}$ & $\%$ & $\mathrm{n}^{0}$ & $\%$ & $\mathrm{n}^{\underline{0}}$ & $\%$ \\
\hline Crianças (28) & 1 & 3,6 & 3 & 10,7 & 24 & 85,7 & $\mathrm{NA}$ & $\mathrm{NA}$ \\
\hline Adolescentes (67) & $\mathrm{NA}$ & $\mathrm{NA}$ & 1 & 1,5 & 51 & 76,1 & 15 & 22,4 \\
\hline Responsável M (48) & $\mathrm{NA}$ & $\mathrm{NA}$ & 15 & 31,3 & 30 & 62,5 & 3 & 6,2 \\
\hline Responsável F (76) & $\mathrm{NA}$ & $\mathrm{NA}$ & 22 & 28,9 & 52 & 68,4 & 2 & 2,6 \\
\hline
\end{tabular}

NA: não aplicável, M: masculino, F: feminino.

Tabela 3 - Distribuição dos usuários e coabitantes, segundo colocação no mercado de trabalho.

\begin{tabular}{lrrrrrr}
\hline & \multicolumn{2}{c}{ Formal } & & \multicolumn{2}{c}{ Informal } \\
\cline { 2 - 3 } & $\mathrm{n}^{0}$ & $\%$ & & $\mathrm{n}^{0}$ & $\%$ \\
\hline Adolescente (67) & 1 & 1,4 & & 31 & 46,2 \\
Responsável feminino (76) & 2 & 2,6 & & 35 & 46,0 \\
Responsável masculino (48) & 18 & 37,5 & & 8 & 16,6 \\
Outros (210) & 13 & 6,1 & & 114 & 54,2 \\
\hline
\end{tabular}

com o sistema de seguro social estabelecida pelos responsáveis biológicos, ficou evidenciado que apenas 12,6\% (12/95) dos menores estariam acobertados pela pensão previdenciária por evento de óbito dos pais. A renda per capita familiar mensal pôde ser expressa pelos seguintes valores em moeda nacional: $61,8 \%$ entre $R \$ 11,00$ e $R \$ 80,00$ (abaixo da linha de pobreza); 31,5\% entre $R \$ 81,00$ e $R \$ 150,00$ e 6,7\% de $R \$ 150,00$ até $R \$ 320,00$. A média de colaboradores nas despesas mensais da família foi de três pessoas, numa relação de um a cinco por família. Na Tabela 4, foram demonstrados os tipos de atividades laborais desenvolvidas pelos adolescentes e a relação principal que tinham com os riscos inerentes à pessoa física e ao impacto na saúde. Apenas um adolescente, aprendiz em estabelecimento bancário, executava uma atividade que, aparentemente, não o fazia correr riscos. 0 tipo de locação/construção das unidades domiciliares e as precárias condições sanitárias em que vivem as famílias são encontrados na Tabela 5. Cerca de 70\% dos domicílios eram próprios e $90 \%$ construídos em alvenaria. No item relativo ao esgotamento de excretas humanas e de águas servidas na área de entorno, foi encontrado que, entre as 76 famílias, 42,1\% (32) tinham uma proximidade de menos de $10 \mathrm{~m}$ com o produto esgotado; 9,2\% (7) entre 10 e $20 \mathrm{~m} ; 5,2 \%$ (4) entre 30 e $40 \mathrm{~m}$ e $43,4 \%$ (33) residiam a uma distância maior que $40 \mathrm{~m}$ do esgotamento sanitário. Onze crianças entrevistadas responderam não saber se o esgotamento sanitário era ou não a céu aberto, tendo sido a resposta fornecida pelos responsáveis. Constatou-se ainda que, em 15,8\% das casas, as excretas humanas eram expostas em via pública ou em caçambas para coleta do lixo. Nenhuma das casas construídas em taipa ou tábua tinha banheiro ou coleta de lixo. A média de densidade de moradores por dormitório foi de 2,6 
Tabela 4 - Relação dos principais riscos à pessoa física e impactos na saúde, segundo o setor produtivo e as tarefas laborativas desenvolvidas por 32 adolescentes ${ }^{21}$.

\begin{tabular}{ll}
\hline Setor/atividade & Riscos/Impactos na saúde \\
\hline Móveis/serra elétrica & $\begin{array}{l}\text { Cortes, traumatismo, choque, inalação } \\
\text { de pó de madeira }\end{array}$ \\
\hline Lixo/manuseio & $\begin{array}{l}\text { Esforço físico, exposição biológica, doenças } \\
\text { da pele, parasitoses, infecções, } \\
\text { cortes por perfurocortantes, com alto teor } \\
\text { de sujidade }\end{array}$ \\
\hline Bar/músico, garçonete & Acesso a drogas lícitas e ilícitas, violência, \\
& prostituição, fadiga, problemas \\
psíquicos
\end{tabular}

Tabela 5 - Características das unidades domiciliares, segundo condições sanitárias básicas das 76 famílias estudadas.

\begin{tabular}{lcc}
\hline Tipo de locação & Número & Porcentagem \\
\hline Própria & 56 & 73,7 \\
Alugada & 7 & 9,2 \\
Cedida & 10 & 13,2 \\
Invadida/ocupada & 3 & 3,9 \\
Material de construção & & \\
$\quad$ alvenaria & 69 & 90,7 \\
$\quad$ taipa/tábua & 7 & 9,2 \\
Existência de banheiro & 40 & 52,6 \\
Esgotamento sanitário & & 75,0 \\
$\quad$ com fossa & 57 & 77,1 \\
$\quad$ suspiro sem tela (57) & 44 & 15,8 \\
$\quad$ a céu aberto & 12 & \\
Destino do lixo doméstico & & 51,3 \\
$\quad$ coletado & 39 & 48,7 \\
$\quad$ a céu aberto & 37 & \\
\hline
\end{tabular}

pessoas, variando de 2 a 14. Foram também incluídos outros cômodos como quarto/dormitório, quando usados como tal. Foram realizadas 12 visitas domiciliares.

\section{DISCUSSÃO}

0 presente estudo reforçou, de forma quantificável, que os usuários infectados com a Wuchereria bancrofti e suas famílias vivem em condições que podem ser qualificadas como desumanas ou subumanas. Isso demonstra a realidade social como cenário para uma perfeita simbiose entre os principais elementos que sustentam a transmissão da Wuchereria bancrofti: o indivíduo infectado, a falta de saneamento básico e a precariedade das condições socioeconômicas que impelem, sem misericórdia, ao contato direto com as suas próprias excretas e ao vetor transmissor. Segundo o relatório da UNICEF de $2003^{14}$, quase $40 \%$ das crianças e dos adolescentes de famílias de baixa renda, quando comparados aos mais ricos, têm 24 vezes mais possibilidades de morarem em domicílios sem acesso ao esgotamento e ao abastecimento da água e, portanto, em adequadas condições para manter a transmissão da parasitose $\mathrm{e}^{1}$. A assertiva já foi defendida por Moraes ${ }^{22}$, quando enfatiza: $A$ determinação da endemia teria a ver com a situação concreta de como vivem os habitantes da cidade. 0 presente estudo leva a reafirmar que o meio ambiente das unidades domiciliares facilitou a proliferação do vetor a partir da constatação que: em quase $80 \%$ das fossas não havia o telamento adequado; que cerca de $15 \%$ das casas colocavam as excretas humanas em via pública ou em caçambas para coleta do lixo; mais de 50\% das famílias conviviam com acúmulo do lixo doméstico nos canais, provocando o transbordamento e, conseqüentemente, o retorno das excretas, num verdadeiro efeito bumerangue; a limpeza das fossas era inadequadamente feita pela comunidade, devolvendo o material orgânico para o meio ambiente. Foi nítida, durante as entrevistas, a falta de indignação dos usuários e responsáveis pela convivência diária com as excretas. Isso contribui para amortecer a própria consciência para uma situação de agravo e que, por sua vez, dificulta o desejo de um movimento coletivo para a melhoria das condições sanitárias do local. Essa percepção pode também ser fruto da convivência de usuários e seus responsáveis com as situações de exclusão social no dia-a-dia. Certamente, vale repetir Braga e cols ${ }^{3}$ que apontam para a necessidade do controle social como pressão para alavancar o processo decisório político. É possível compreender, sem muita elaboração, as más condições do repouso noturno dos coabitantes: a média foi de quase três indivíduos por dormitório, tendo sido encontradas até 14 pessoas dividindo o mesmo dormitório em casas de apenas um vão. Não fez parte da pesquisa a quantificação da área construída de cada residência, mas as visitas à comunidade, para melhor conhecer a realidade reportada por alguns entrevistados, revelaram que a área física da grande maioria dos quartos tinha um espaço inferior a $2 \mathrm{~m}^{2}$. A literatura mostra que a prevalência de microfilaremia em familiares, quando um membro é detectado positivo, é de seis vezes maior que na população geral do mesmo bairro ${ }^{13}$. Isso evidencia que, na população estudada, as chances são máximas de estar ocorrendo a facilitação da transmissão durante 0 repouso noturno, uma vez que o vetor da bancroftose, em nosso país, tem hábitos hematófagos noturnos.

Não causou surpresa o fato de existir uma grande prevalência de casas próprias, pois os terrenos são, também em sua maioria, locais de antigas invasões/ocupações - estratégia geralmente usada pela população de baixa ou nenhuma renda para construir a sua moradia e/ou escapar de aluguéis que não conseguiriam pagar.

No contexto social, é impossível isolar o estado da infância ou da adolescência da situação concreta vivida pela família. São vertentes aglutinadas. 0 desemprego dos responsáveis revelou que as mesmas pressões sofridas por eles para conseguirem um lugar ao sol no mundo do trabalho se deslocaram para os usuários, levando-os a manter contato com a vida produtiva para ajudar em casa, antes do momento ideal recomendado. E, pior ainda, pois já sentem na pele a subalternização e a insegurança 
no sistema de trabalho informal sem o conhecimento dos meios de proteção social e legal que possuem. Foi emblemática a frase de um dos adolescentes que conseguiu refletir a realidade de sua relação com o empregador e a visão que, provavelmente, tem da vida de trabalho informal de seus pais: ... meu sonbo é ter a carteira assinada. Não importa em que atividade. Se, por um lado, o trabalho precoce deu-lhes a oportunidade de contribuir para as despesas da casa, pôde também lhes ter oferecido, no espaço das atividades desenvolvidas, o contato com situações de risco pessoal. Apenas um adolescente exercia atividade que, aparentemente, não o fazia correr risco (aprendiz em agência bancária). Se o espelho retrovisor desses adolescentes tivesse sido o grau de maturidade educacional dos pais, obviamente a esperança de um futuro melhor teria sido repensada e a fase de qualificação, através da educação formal, não teria sido abortada. A literatura mostra que os filhos cujas mães têm escolaridade menor que um ano, têm quatro vezes mais chances de estarem trabalhando entre os 10 e os 15 anos de idade e onze vezes mais chances de não freqüentarem a escola, quando comparados àqueles cujas mães estudaram, pelo menos, onze anos. Entre crianças em idade pré-escolar, 56,8\% não freqüentam escola quando as mães têm menos de um ano de escolarização. Esse percentual cai para 16,9\% quando as mães têm 11 ou mais anos de estudo. A literatura mostra que o nível educacional das mães é um dos fatores importantes no impacto socioeconômico e educacional das crianças e dos adolescentes. A média nacional é de $45 \%$ de crianças e adolescentes pobres, mas, quando as mães têm escolaridade menor que um ano, esse índice se eleva para $76 \%{ }^{14}$. No presente trabalho, cerca de $30 \%$ das mães eram analfabetas e quase $70 \%$ abandonaram os estudos no ensino fundamental.

As condições socioeconômicas das famílias mostraram sua fragilidade para manter os jovens em salas de aula e, ao mesmo tempo, sua pressão para que permaneçam em trabalhos informais, uma equação desigual e pérfida. Foi observado que havia cerca de 43\% dos usuários com idade três a nove anos superior à idade oficial para a série que cursavam. 0 abandono da escola durante o ensino fundamental e a defasagem entre a idade oficial e a série cursada não pareceram contraditórios à informação dada pelos usuários como justificativa de trabalhar para ajudar em casa (dados não publicados pelos autores). Os autores acreditam que essa justificativa não tenha influenciado, de forma isolada, a fuga dos bancos escolares ou o atraso escolar. Vale ressaltar que, de forma até certo ponto não esperada, o estudo verificou que não ocorreu defasagem da faixa etária entre os que cursavam o ensino médio, não sendo possível para os autores, com base nas informações coletadas, conhecer os motivos disso.

Outro dado que chamou a atenção dos pesquisadores foi a replicação da ingesta alcoólica dos familiares na conduta dos adolescentes. Foi preocupante a declaração de uma criança de nove anos de idade que experimentava a cerveja da mãe quando essa estava em estado de embriaguez. Apesar de isolado, o fato revela a vulnerabilidade sociocultural dos jovens ao álcool o qual transpõe o apelo da mídia e é acessado dentro ou próximo da casa, o que ajuda a banalizar os riscos, que não são apenas físicos e psíquicos, mas também de inter-relacionamento social.
A atividade sexual pareceu iniciar-se numa tênue linha entre a infância e a adolescência. Isso alertou para uma situação preocupante, devida tanto às questões de risco para infecções sexualmente transmissíveis, quanto à possibilidade de todas as implicações sociais presentes numa gestação em fase etária ainda imatura e que vão desde a rutura com a vida estudantil até a reprodução das mesmas condições sociais para o filho gerado. Nenhum deles referiu abortamento. As gestações de três adolescentes (com idade variando de 14 a 16 anos) ocorreram em encontros ocasionais, quando não foi possível obter o preservativo pelas mais diversas razões (dados não apresentados), contradizendo assim a informação obtida de todos os adolescentes: faziam uso regular de preservativo. Nem todas as respostas negativas para a atividade sexual puderam ser consideradas como verdadeiras, pois as entrevistas foram realizadas com a presença de um responsável, o que poderia inibir os adolescentes ou fazê-los reativos se a resposta os colocasse em confronto direto com a imagem que possuem dentro da família. É também válida essa afirmação para as respostas negativas quanto ao uso de drogas ilícitas, fato que pôde, no seguimento dos casos (embora não fizesse parte desse estudo), ser mais bem revelado pela vivência de um considerável número de crianças e de adolescentes no mundo da droga e da violência entre gangues rivais em bairros periféricos. Salienta-se que todos os dados apresentados neste estudo foram obtidos no primeiro momento da relação profissional com os usuários.

Chamou a atenção a solidariedade de parentes ou de pessoas estranhas à família biológica, quando tomaram os menores sob os seus cuidados, principalmente quando se observa que eram pessoas componentes de um contingente populacional da pobreza e que conviviam com o apelo das necessidades básicas pessoais e de seus próprios familiares.

A aplicação dialógica da entrevista permitiu a obtenção de informações não previstas no questionário e que se revelaram importantes em adicionar dados à leitura crítica da realidade social. Embora carecendo de um maior aprofundamento por estudos adicionais, principalmente para comparações com outras áreas endêmicas não só do Grande Recife mas de outros países, os resultados apresentados já sugerem, fortemente, a relevância transdisciplinar ${ }^{18}$ para a planificação de programas que possam ser impactantes na saúde da criança e do adolescente vivendo em áreas endêmicas para bancroftose. As múltiplas facetas desse mundo de carências e a revelação das condições sociais demonstraram que a realidade não pode ser pensada isoladamente como um dado subjetivo dentro da concretude dos casos clínicos e apenas do ponto de vista do infectologista ou do pediatra. Também mostrou, nas entrelinhas, a necessidade de grupos institucionais se articularem e utilizarem a informação para a saúde, de forma que se possa, um dia, garantir o direito continuado à acessibilidade aos serviços e aos bens públicos para a manutenção da saúde. Poder-se-ia aqui trazer as considerações de Vasconcelos ${ }^{30}$.... o profissional sem um estudo da demanda não tem condições de pensar as estratégias de ação a serem empreendidas... .

Esses menores participaram de um tratamento que é, como ocorre na maioria das doenças infantis, o reverso do prazeroso 
e do lúdico, o mundo das consultas agendadas, das coletas de sangue, das medicações tomadas. Com cuidado, foram repassadas aos responsáveis as informações gerais de uma potencial evolução da fase de infecção assintomática para a doença clínica (principalmente a hidrocele e o linfedema de membros inferiores), enfatizando-se quão importante seria a pesquisa regular da microfilária de todos na família. Foi dada, assim, a orientação de procurar o posto de saúde mais próximo, pelo menos anualmente. Foi esclarecido também, e principalmente, que 0 tratamento antifilarial feito no presente não protege os usuários de doença clínica futura, uma vez que continuarão sob o risco de infecção, caso as condições em que vivem não sejam melhoradas de forma substancial. Enquanto essa mudança não ocorre, o fantasma de desenvolver a doença crônica, com as suas severas consequiências na qualidade de vida dos portadores, acompanhará não só os usuários, mas todos os indivíduos vivendo nas comunidades endêmicas ${ }^{719}$. Se o que está em jogo é sempre a melhoria da qualidade de vida de uma população, dificilmente se chegará a ela se o construto desse trabalho for apenas dirigido pela Secretaria Municipal de Saúde, sem a parceria das Secretarias locais que respondem por educação, meio ambiente e infra-estrutura sanitária e por políticas de trabalho e renda. Apesar de todos os limites existentes e de todas as possibilidades que teimam em não se fazer presentes na vida desses usuários, é necessário ter uma visão diferente para se definir o tipo de atenção da saúde ampliada a ser posta à disposição para essa parcela da população. Um fosso se abre quando o conhecimento do setor saúde exige a resposta que deveria se fazer ouvir, ou seja, o reconhecimento estatal de que a bancroftose permanece porque falta saneamento em áreas onde a transmissão é pelo Culex quinquefasciatus. As condições subumanas de moradia da população atingida pelo agravo agem como um forte co-fator social, trazendo à baila a dissociação entre o poder decisório das políticas públicas e as evidências científicas. 0 parasita tira vantagens das condições do subdesenvolvimento e vem como mais um agravo para a população, já tão fragilizada pela falta de controle social na política de saúde pública do Brasil. A adoção de práticas estatizadas, como o saneamento, não mais necessita de argumentos de defesa. Especificamente em relação à filariose, esse seria o caminho mais curto e definitivo, já que o vetor melhor se reproduz em águas contaminadas por excretas humanas. A prevenção é essencialmente um ato político; penetra nas teias dos poderes constituídos pela sociedade e deveria ser articulada com a sociedade civil organizada para responder, com alternativas de solução, às necessidades dessa parcela de cidadãos alijados dos seus direitos de viver com dignidade.

Diante da realidade social encontrada, sobra aos autores um sentimento misto de impotência e de constrangimento quando, após esclarecerem acerca da transmissão, têm o conhecimento que a melhoria da saúde desses indivíduos não depende apenas do seguimento das orientações médicas detalhadamente feitas e assimiladas, mas fica à mercê de uma decisão política para refazer um ambiente que não propicie a reinfecção. Nesse caso, a filariose é diferente de tantas outras doenças infecciosas para as quais 0 maior agravo - desde que tenham sido gerados um processo de informação assimilável e recursos disponibilizados à população
- é a falta de decisão individual para evitar a contaminação. Nesse ciclo de vida da infância e da adolescência, maior vulnerabilidade é gerada quando existe a exclusão social através da violação dos seus direitos, independentemente de viverem ou não em áreas endêmicas de filariose. Há, provavelmente, uma desigualdade muito mais sutil dentro da pobreza, que parece tão homogênea. Não pode continuar existindo a invisibilidade da diferença (ou a visibilidade da indiferença), quando essa pobreza co-existe com uma situação de infecção pela Wuchereria bancrofti e por todos os males que ela pode determinar no futuro desses menores que foram surpreendidos positivos ${ }^{9}$ e de tantos outros que nunca saberão que, um dia, foram infectados, até apresentarem a forma crônica da doença.

Recomendações. 0 presente estudo fortalece a certeza de que toda a realidade social é um construto dependente de uma interpretação que sugere encadeamentos inter e transdisciplinares e um alerta para potenciais fatores que possam interferir na cobertura mínima da população elegível para o tratamento antifilarial em massa recomendado pela Organização Mundial da Saúde ${ }^{23}$. Poderiam ser lembrados o hábito social de ingesta alcoólica e a precocidade do trabalho; a questão da paridade, na fase etária estudada, pois a gestante deve ser excluída do processo até 0 ano seguinte e, nesse meio tempo, se não houver um controle de busca ativa, poderá estar novamente grávida no próximo tratamento em massa e, assim, ser excluída do processo novamente. 0 conhecimento desses dados e o planejamento adequado para garantir o tratamento do indivíduo faltoso, assegurando a cobertura mínima, pode influenciar o sucesso ou 0 fracasso em interromper a transmissão ao longo dos 5-6 anos de tratamento antifilarial em massa ${ }^{17}$.

\section{AGRADECIMENTOS}

Os autores agradecem em especial às crianças e aos adolescentes de Jaboatão dos Guararapes e aos seus responsáveis, pela confiança depositada nos pesquisadores envolvidos no estudo; à equipe do Programa de Filariose da Secretaria de Saúde de Jaboatão dos Guararapes, na pessoa da Dra ${ }^{\mathrm{a}}$ Elizeide Meireles, e a todos que fazem o NEPAF, pelo profissionalismo com os usuários e seus familiares; à ONG Amaury Coutinho, pelo suporte financeiro necessário ao desenvolvimento do presente estudo; à $\mathrm{Dr}^{\mathrm{a}}$ Anne Dreyer e à Dra Maria de Fátima Militão de Albuquerque, pelas valiosas sugestões no manuscrito original.

\section{REFERÊNCIAS}

1. Albuquerque MFPM. Urbanização, favelas e endemias: a produção da filariose no Recife, Brasil. Cadernos de Saúde Pública 9: 487-497, 1993.

2. Babu BV, Nayak AN. Treatment costs and work time loss due to episodic adenolymphangitis in lymphatic filariasis patients in rural communities of Orissa, India. Tropical Medicine and International Health 8: 1102-1109, 2003.

3. Braga C, Albuquerque MFPM, Morais HM. A produção do conhecimento científico e as políticas de saúde pública: reflexões a partir da ocorrência da filariose na cidade do Recife, Pernambuco, Brasil. Cadernos de Saúde Pública 20: 351-361, 2004. 
4. Braga C, Albuquerque MFPM, Schindler H, Silva MRF, Maciel A, Furtado A, Carvalho AB, Souza W, Ximenes RAA. Risk factors for the occurence of bancroftian filariasis infection in children living in endemic areas of Northeast of Brazil. Journal of Tropical Pediatrics 44: 87-91, 1998.

5. Diário Oficial da União/Brasil. Estatuto da Criança e do Adolescente. Lei nº 8.069, de 13 de julho de 1990, art. 2º, Brasília, DF, 16/07/1990, 1990.

6. Dreyer G, Figueredo-Silva J, Carvalho K, Amaral F, Ottesen EA. Lymphatic filariasis in children: adenopathy and its evolution in two young girls. The American Journal of Tropical Medicine and Hygiene 65: 204-207, 2001.

7. Dreyer G, Norões J, Addiss D. The silent burden of sexual disability associated with lymphatic filariasis. Acta Tropica 63: 57-60, 1997.

8. Dreyer G, Noroes J, Addiss D, Santos A, Medeiros Z, Figueredo-Silva J. Bancroftian filariasis in a paediatric population: an ultrasonographic study. Transactions of the Royal Society of Tropical Medicine and Hygiene 93: 633-636, 1999.

9. Dreyer G, Noroes J, Figueredo-Silva J. Elimination of lymphatic filariasis as a public health problem. New insights into the natural history and pathology of bancroftian filariasis: implications for clinical management and filariasis control programs. Transactions of the Royal Society of Tropical Medicine and Hygiene 94: 594-596, 2000.

10. Evans DB. Social and economic factors and the control of lymphatic filariasis: a review. Acta Tropica 53: 1-26, 1993.

11. Figueredo-Silva J, Dreyer G. Bancroftian filariasis in children and adolescents: clinical-pathological observations in 22 cases from an endemic area. Annals of Tropical Medicine and Parasitology 99: 759-769, 2005.

12. Fontes G, Braun RF, Fraiha Neto H, Vieira JBF, Padilha SS, Rocha RC, Rocha EMM. Filariose linfática em Belém, Estado do Pará, Norte do Brasil e a perspectiva de eliminação. Revista da Sociedade Brasileira de Medicina Tropical 38: 131-136, 2005.

13. Fontes G, Brito AC, Calheiros CM, Antunes CM, Rocha EMM. Situação atual da filariose bancroftiana na cidade de Maceió, Estado de Alagoas, Brasil. Cadernos de Saúde Pública 10: 293-300, 1994.

14. Fundo das Nações Unidas para a Infância. Dados sobre a infância e a adolescência: diversidade e eqüidade no Brasil. In: Situação da Infância e da Adolescência Brasileiras, p. 50-70, 2003. Disponível em: <http://www.unicef.org/brazil/ siab_capitulo2a.pdf (Acessado em: 15 set 2005), 2003.

15. Instituto Brasileiro de Geografia e Estatística. Pesquisa nacional por amostra de domicílios. Notas técnicas. Volume 23, 2002. Disponível em: <www.ibge.gov. br/home/estatistica/populacao/trabalhoerendimento/pnad2002/notas_brasil. pdf $>$. (Acessado em: 9 jul, 2005), 2002.

16. Lowman EW. Incidence of filariasis in children. United States Naval Medical Bulletin 42: 341-343, 1944.

17. Mathieu E, Direny AN, De Rochars MB, Streit TG, Addiss DG, Lammie PJ. Participation in three consecutive mass drug administrations in Leogane, Haiti. Tropical Medicine and International Health 11: 862-868, 2006.

18. Mattos D, Dreyer G. A filariose bancroftiana: uma perspectiva psicossocial e política para os profissionais da saúde. Revista Panamericana de Infectologia 8: 35-39, 2006
19. Mattos D, Drever G. Elefantíase em área de filariose bancroftiana: o lado humano da doença. Revista de Patologia Tropical 35: 117-124, 2006.

20. Medeiros Z, Dreyer G, Andrade L, Pires ML, Mendes J, Pimentel R. Wuchereria bancrofti microfilarial density of autochthonous cases and natural Culex infectivity rates in Northeast Brazil. Journal of Tropical Medicine and Hygiene 95: 214-217, 1992.

21. Ministério da Saúde. Secretaria de Atenção à Saúde, Departamento de Ações Programáticas Estratégicas. Trabalho Infantil: diretrizes para atenção integral à saúde de crianças e adolescentes economicamente ativos. Brasília, DF, 2005.

22. Moraes HMM. A filariose no Recife. Um estudo epidemiológico. Dissertação de Mestrado, Universidade de São Paulo, São Paulo, SP, 1982.

23. Ottesen EA, Ismail MM, Horton J. The role of albendazole in programmes to eliminate lymphatic filariasis. Parasitology Today 15: 382-386, 1999.

24. Programa das Nações Unidas para o Desenvolvimento Brasil. Pobreza e fome. Objetivo 1: erradicar a extrema pobreza e a fome. Belo Horizonte, Universidade Federal do Rio Grande do Sul, Pontifícia Universidade Católica Minas/Instituto de Desenvolvimento Humano Sustentável, p. 6, 2004.

25. Rajasekariah GR, Parab PB, Chandrashekar R, Deshpande L, Subrahmanyam D. Pattern of Wuchereria bancrofti microfilaraemia in young and adolescent school children in Bassein, India, an endemic area for lymphatic filariasis. Annals of Tropical Medicine and Parasitology 85: 663-665, 1991.

26. Rajendran R, Sunish IP, Mani TR, Munirathinam A, Satyanarayana K. Targeting of children in filariasis mass drug administration. The Lancet 360: 1430, 2002.

27. Ramaiah KD, Das PK, Michael E, Guyatt H. The economic burden of lymphatic filariasis in India. Parasitology Today 16: 251-253, 2000.

28. Rizzo JA, Belo C, Lins R, Dreyer G. Children and adolescents infected with Wuchereria bancroft $i$ in Greater Recife, Brazil: a randomized, year-long clinical trial of single treatments with diethylcarbamazine or diethylcarbamazinealbendazole. Annals of Tropical Medicine and Parasitology 101: 423-433, 2007.

29. Sociedade Brasileira de Cardiologia/Sociedade Brasileira de Hipertensão/ Sociedade Brasileira de Nefrologia. Tratamento Não-Medicamentoso. In: V Diretrizes Brasileiras de Hipertensão 2006. São Paulo, página 20-22, 2006. Disponível em: <http://www.sbh.org.br/novo/arquivos/documentos/14.pdf. (Acessado em: 3 mar 2007), 2006.

30. Vasconcelos AM. A prática do serviço social: cotidiano, formação e alternativas na área da saúde. $2^{\text {a }}$ edição, Editora Cortez, São Paulo, p. 450, 2003.

31. World Health Organization. The world health report 1995: bridging the gaps. Geneva, 1995. Disponível em: <http://www.who.int/whr/previous/en/index.html. (Acessado em: 9 jul, 2005), 1995.

32. World Health Organization. Global programme to eliminate lymphatic filariasis Weekly Epidemiological Record 80: 202-212, 2005.

33. World Health Organization. The world health report 2006: working together for health. Geneva, 2006. Disponível em: <http://www.who.int/whr/en/>. (Acessado em: 9 jan, 2007), 2006 